\title{
Antioxidant, total phenolic, ascorbic acid and color changes of Ocimum bacili- cum $L$. by sun and microwave drying
}

\section{Özlem Turgay1® ${ }^{1}$, Yusuf Esen®}

Cite this article as:

Turgay, Ö., Esen, Y. (2020). Antioxidant, total phenolic, ascorbic and changes of Ocimum basilicum L. by sun and microwave drying. Food and Health, 6(2), 110-116. https://doi.org/10.3153/FH200012

${ }^{1}$ University of Kahramanmaras Sütçü İmam, Department of Food

Engineering, Kahramanmaraş, Turkey

${ }^{2}$ Technical Sciences, University of Ardahan, Vocational School Department of Food Technology, Ardahan, Turkey

ORCID IDs of the authors:

Ö.T. 0000-0003-2286-833X

Y.E. 0000-0003-1173-0677

Submitted: 02.07 .2019

Revision requested: 10.11 .2019

Last revision received: 02.12 .2019

Accepted: 15.12 .2019

Published online: 24.02 .2020

Correspondence: Özlem TURGAY

E-mail: ozlem $@$ ksu.edu.tr

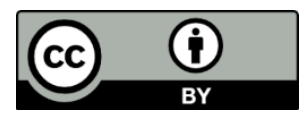

(C) Copyright 2020 by ScientificWebJournals Available online at

http://jfhs.scientificwebjournals.com

\begin{abstract}
Basil is a plant consumed fresh and dried in Mediterranean cuisine. The effect of drying on antioxidant activity, total phenolic content, ascorbic acid content and color of Ocimum bacilicum L. from Turkey was investigated. The samples were dried by two methods: sun drying (RH 43-55\% for 2 days) and microwave drying (400 watts for $8 \mathrm{~min}$ ). Total phenolics contents were ranged from 34.1 to $62.2 \mathrm{mg} \mathrm{GAE} / \mathrm{g} \mathrm{DM}$ ). The antioxidant activity based on the $\mathrm{DPPH} \mathrm{IC}_{50}$ assay of the basil extracts varied from 104 to 149.7. The initial content of ascorbic acid in basil was $134.3 \mathrm{mg} /$ $100 \mathrm{~g}$. The ascorbic acid content of sun and microwave dried samples were $32.5,25.5 \mathrm{mg} / 100 \mathrm{~g}$, respectively. The values for the $L^{*}, a^{*}$ and $b^{*}$ coordinates of the fresh basil were $55.14,-17.13$ and 27.76, sun and microwave dried basil samples were 45.63, -1.73, 16.79, and 39.17, -12.19, 21.62 , respectively. As a result of this study, it was determined that dried basil samples contain more total phenolic component and have more antioxidant activity than fresh basil samples. It is also possible to deduce from the results that heat-drying causes high levels of ascorbic acid degradation and causes significant changes in color materials.
\end{abstract}

Keywords: Ocimum bacilicum L., Antioxidant activity, Total phenolic content, Ascorbic acid content 


\section{Introduction}

Polyphenols are responsible for various health benefits and suggested to be a major bioactive compound of plants. Antioxidants play a major role to avoid food degradation, prevent many diseases and aging. Recent researches have shown that the consumption of plant polyphenols may protect against the cardiovascular disease and certain forms of cancer (Gross, 2004; Neuhouser, 2004). Intake of natural antioxidants could be increased body defense mechanism as anticarcinogen (Ames, 1983). Lots of plants, spices and herbs contain antioxidative, antimicrobial, antimutagen and other nutritional constituents in their tissues (Ateş and Erdoğrul, 2003; Erdoğrul, 2002; Simon et al., 1999).

Basil is known for its substantial genetic heterogeneity with between 65 and 150 species (Makri and Kintzios, 2007). Ocimum bacilicum L. or basil is a worldwide cultivated plant under a variety of ecological conditions but originating in warm tropical climates of India, Africa and southern Asia (Putievsky and Galambosi, 1999). Basil can used traditionally as culinary in the Mediterranean and Southeast Asian foods. It is using in the treatment of a headache, cough, diarrhea and kidney malfunctions, against insect bites, acne and it has long been used to flavor foods, as well as dental and oral products (Simon et al., 1984). Local sweet basil, lemon basil, purple ruffle and mintier Egyptian basil are most commonly used in European and American cuisine.

One of the oldest methods of preserving foods is drying or desiccation. The preservation of foods by drying is a direct removal or binding of moisture, which stops the growth of microorganisms. The content of the moisture of the vegetables should be reduced below $4 \%$ to have satisfactory storage life and quality (Jay, 2000). Fruits, vegetables and herbs are often dried by sunlight. Studies about the different drying methods on different matrixes have been attracting the attention of scientists.

Main objectives of this work were to study the antioxidant activity, total phenolic content, ascorbic acid content and color of Ocimum bacilicum L. from Turkey and effect of drying to these parameters were also determined.

\section{Materials and Methods}

All parts of cultivated Ocimum bacilicum L. were purchased from Kahramanmaraş local markets during summer (JuneJuly 2018). Fresh, sun and microwave dried leaves of basil samples were analyzed according to their antioxidant activity, ascorbic acid content, total phenolic content and color changes in three replicates. Taxonomic identification of the samples was conducted by the KSU Department of Biology.

\section{Extraction}

For both fresh and dried samples, $1 \mathrm{~g}$ of basil samples extracted into $20 \mathrm{~mL}$ of acidified (with $1 \%$ hydrochloric acid, $\mathrm{v} / \mathrm{v})$ methanol $(80 \%)$ on a shaker $(170 \mathrm{rpm})$ for $2 \mathrm{~h}$ and filtered by Whatman paper (No:4). The same extract was used for both total phenolic content and antioxidant activity analysis.

\section{Total Phenolic Content}

The concentration of total phenols in extracts was measured by UV spectrophotometer (PG Instruments 25 UV/VIS), based on a colorimetric oxidation/reduction reaction. The oxidizing agent was Folin-Ciocalteu reagent (Merck) (Ranilla et al., 2010). For this purpose, $0.1 \mathrm{~mL}$ of diluted methanol extract $(1 \%)$ and $2 \mathrm{~mL}$ of $\mathrm{Na}_{2} \mathrm{CO}_{3}(2 \%)$ was added and incubated for 5 minutes, $0.1 \mathrm{~mL}$ of Folin-Ciocalteu reagent was added and incubated for $60 \mathrm{~min}$ at room temperature in the dark. Distilled water was used for a control sample. The absorbance was measured at $760 \mathrm{~nm}$. The results are expressed as $\mathrm{mg}$ gallic acid equivalents $/ 1 \mathrm{~g}$ in dry matter (mg GAE/g $\mathrm{DM})$.

\section{DPPH Scavenging Activity}

The capacity to scavenge the 2,2-diphenyl-1-picrylhydrazyl (DPPH) (Sigma) free radical was monitored according to a method reported before (Hatano et al., 1988). Various concentrations of sample extracts $(0.1,0.2,0.3 \mathrm{~mL})$ were mixed with $(2.9,2.8,2.7 \mathrm{~mL})$ methanol and $1 \mathrm{~mL}$ of methanolic solution containing DPPH radicals $(0.1 \mathrm{mM})$ added to the mixture. The mixture was shaken hard and left in the dark until stable absorption values were obtained. The reduction of the DPPH radical was measured by monitoring continuously the decrease in absorption at $517 \mathrm{~nm}$. DPPH scavenging effect was calculated as a percentage of DPPH discoloration using the equation: \% scavenging effect $=\left[\left(\mathrm{A}_{\mathrm{DPPH}}-\mathrm{A}_{\mathrm{S}}\right) / \mathrm{A}_{\mathrm{DPPH}}\right]$ $\mathrm{x} 100$, where $\mathrm{A}_{\mathrm{S}}$ is the absorbance of the solution when the sample extract has been added at a particular level and $\mathrm{A}_{\mathrm{DPPH}}$ is the absorbance of the DPPH solution. Scavenging activity in this assay was expressed as IC50, which represents the concentration of the extract $(\mathrm{mg} / \mathrm{mL})$ required to inhibit $50 \%$ of the free radical-scavenging activity. Butylated hydroxytoluene (BHT) was used as a positive control.

\section{Ascorbic Acid Content}

A $10 \mathrm{~mL}$ aliquot of the sample was placed into a $100 \mathrm{~mL}$ volumetric flask and brought to volume with $0.4 \%$ oxalic acid solution. The solution was filtered by Whatman No. 4 filter paper. A $10 \mathrm{~mL}$ aliquot of the filtered solution was pipetted into a conical flask along with $15 \mathrm{~mL}$ of $0.4 \%$ oxalic acid solution. The solution was titrated, using a microburette, with 
$0.04 \%$ aqueous sodium dichlorophenolindophenol solution to the first pink shade. The sodium dichlorophenolindophenol solution was standardized with sodium thiosulfate $0.01 \mathrm{~N}$, in a matrix of potassium iodide $(50 \%)$ and $\mathrm{HCl} 1 \mathrm{~N}$ using starch as an indicator. The absorbance was measured at $518 \mathrm{~nm}$. The results were expressed in $\mathrm{mg} / 100 \mathrm{~g}$ for both fresh and dried samples (Hış11, 1993).

A $10 \mathrm{~mL}$ portion of the sample was put in a $100 \mathrm{~mL}$ volumetric flask and completed to the target volume with an oxalic acid solution that is $0.4 \%$. The solution was filtered through Whatman No 4 filter paper. A $10 \mathrm{~mL}$ aliquot of the filtered solution was pipetted into the erlenmeyer with $15 \mathrm{~mL}$ of $0.4 \%$ oxalic acid solution. The solution was titrated by a microburette with $0.04 \%$ aqueous sodium dichlorophenolindophenol solution until the appearance of the first pink tone.

\section{Drying of the Basil Samples}

Samples were dried by using two methods, sun drying (RH $43-55 \%$ for 2 days) and microwave drying (400 watts for 8 $\min )$.

\section{Color Measurement}

Color measurement was made before drying and after other drying procedures a Konica Minolta CR-400 model colorimeter. The instrument was standardized each time with a white and a black ceramic plate. The color values were expressed as $L$ (whiteness or brightness/darkness), $a$ (redness/greenness) and $b$ (yellowness/blueness) at any time, respectively $\left(L^{*}=97.45, a^{*}=0.00, b^{*}=1.77\right)$. The total color change $\left(\Delta E=\sqrt{\left(L_{0}-L_{1}\right)^{2}+\left(a_{0}-a_{1}\right)^{2}+\left(b_{0}-b_{1}\right)^{2}}\right)$, was the parameter considered for the overall color difference evaluation (Demirhan and Özbek, 2009).

\section{Statistical Analysis}

The results of the analysis were subjected to one-way analysis of variance (ANOVA) using a general linear model (GLM) procedure in the SPSS software (SPSS Inc., Chicago, IL). The means were compared for significance at the $5 \%$ level using Duncan's multiple range tests.

\section{Results and Discussion}

The average concentration of total phenolic content, DPPH scavenging activity and ascorbic acid content of the basil samples were presented in Table 1. Color measurement of the fresh, sun and microwave dried samples were presented in Table 2.

The amount of total phenolics ranged from 34.1 to $62.2 \mathrm{mg}$ GAE/g DM. Fresh basil' s total phenolic content was determined as $34.1 \mathrm{mg} \mathrm{GAE} / \mathrm{g}$ DM and consistent with the results of Gajula et al. (2009), Javanmardi et al. (2003) and Hossain et al. (2010) studies on different types of fresh basil samples. However, it was seen that it is higher than the results of Śledź et al. (2013), Bušić et al. (2014), Siti Mahirah et al. (2018) studies. The highest total phenolic content was detected in microwave dried samples as $62.2 \mathrm{mg} \mathrm{GAE} / \mathrm{g} \mathrm{DM}$. It was determined that this result was higher than the results of Bušić et al. (2014).

The antioxidant activity based on the DPPH $\mathrm{IC}_{50}$ assay of the basil extracts varied from 104 to 149.7. The antioxidant activity of fresh basil was determined as 149.7. This result was consistent with the results of Gajula et al. (2009) and Bayala et al. (2014) studies. But it was found that higher than the results of Bušić et al. (2014). The highest antioxidant activity was detected in microwave dried samples as 104 (Table1). All of the total phenolic contents and antioxidant activity results were in the range of the previous similar studies.

Table1. The Average Concentration of Total Phenolic Content (TPC), DPPH Scavenging Activity (DSA), Ascorbic Acid Content (AAC) of Basil Samples

\begin{tabular}{|l|c|c|c|}
\hline Sample & $\begin{array}{c}\text { TPC } \\
(\mathrm{mg} \mathrm{GAE} / \mathrm{g} D M)\end{array}$ & $\begin{array}{c}\text { DSA } \\
\left(\mathrm{IC}_{50}\right)\end{array}$ & $\begin{array}{c}\text { AAC } \\
(\mathrm{mg} / 100 \mathrm{~g})\end{array}$ \\
\hline Fresh basil & $34.1^{\mathrm{a}}$ & $149.7^{\mathrm{b}}$ & $134.3^{\mathrm{a}}$ \\
\hline Sun-dried & $48.2^{\mathrm{c}}$ & $129.5^{\mathrm{b}}$ & $32.5^{\mathrm{b}}$ \\
\hline Microwave-dried & $62.2^{\mathrm{b}}$ & $104^{\mathrm{a}}$ & $25.5^{\mathrm{c}}$ \\
\hline
\end{tabular}

Table 2. Color measurement of the fresh, sun and microwave dried basil samples

\begin{tabular}{|l|c|c|c|c|c|c|}
\hline Sample & $\mathbf{L}^{*}$ & $\mathbf{a}^{*}$ & $\mathbf{b}^{*}$ & Chroma & Hue & $\Delta \boldsymbol{E}$ \\
\hline Fresh basil & 55.14 & -17.13 & 27.76 & 32.62 & -35.46 & \\
\hline Sun-dried & 45.63 & -1.73 & 16.79 & 16.88 & -5.85 & 21.16 \\
\hline Microwave-dried & 39.17 & -12.19 & 21.62 & 24.82 & -32.29 & 17.81 \\
\hline
\end{tabular}

$L$ (whiteness or brightness/darkness), $a$ (redness/greenness), $b$ (yellowness/blueness) 
Average antioxidant capacities for the fresh, sun and microwave dried basil samples in this study were determined using DPPH free-radical scavenging assay. It is one of the most commonly used methods to evaluate antioxidant capacity. The 2,2-diphenyl-2-picrylhydrazyl radical has been used to evaluate the free radical scavenging capacity of antioxidants $(\mathrm{Yu}, 2001)$. It is possible to determine the antiradical power of an antioxidant activity by measurement of the decrease in the absorbance of DPPH- at $517 \mathrm{~nm}$. The color change from purple to yellow, the absorbance decreased when the DPPHwas scavenged by an antioxidant, through the donation of hydrogen to form a stable DPPH- molecule. This molecule had an absorbance at $517 \mathrm{~nm}$ in the radical form which disappeared after acceptance of an electron or hydrogen radical from an antioxidant compound to become a stable diamagnetic molecule (Matthäus, 2002)

The Folin-Ciocalteu assay to determine total phenolic concentrations is based on an electron transfer mechanism, and typically has a high degree of linear correlation with DPPH antioxidant capacity. This result also seemed in this study. Furthermore, it has been found that the total amount of phenolic content is better preserved in microwave type drying than in natural drying methods (sun) (Açıkgöz et al., 2015). As reported in a study about the effects of drying on total phenolics of grape skins (Chism et al.,1996), phenolic compounds are frequently found in the outer areas of vacuoles. Thus, phenolic compounds stored outside the organelles are also more susceptible to degradation due to degradation of the cell structure during the drying process (de Torres et al., 2010).

Medicinal plants are used in different types of products as fresh, dried and stored forms (Lin et al., 2011). Methods of using different drying can be performed. Dehydration is one of important preservation method, because it inhibits enzymatic degradation and limits microbial growth (Harbourne et al., 2009; Muller and Heinds, 2006). Normally, the antioxidant (phenolic compounds, vitamins, etc.) content of fresh plant materials is higher than that of dried plant materials, these are degraded during drying. Some recent studies have shown that dried plant materials contain higher antioxidants, such as polyphenols, and antioxidant activity as compared to fresh plant materials (Chang et al., 2006; Choi et al., 2006). Drying also affected the antioxidant activity of fruits and vegetables differently (Choi et al., 2006; Kuljarachanan et al., 2009). The initial content of ascorbic acid in fresh basil was $134.3 \mathrm{mg} / 100 \mathrm{~g}$. This result was consistent with the result of Bušić et al. (2014) study. The ascorbic acid content of sun and microwave dried samples were $32.5,25.5 \mathrm{mg} / 100 \mathrm{~g}$, respectively and the differences were statistically important. The degradation of ascorbic acid is considerably affected by the drying conditions, causing losses in almost every case. In addition, Bušić et al. (2014) also reported a decrease in ascorbic acid content of about $22 \%$ with drying. Generally, every kind of processing procedure has been decreased nutritional value of fruits and vegetables compared to the fresh samples (Barbosa-Canovas et al., 2008). The decrease of ascorbic acid occurs as the oxidation of ascorbic acid to dehydroascorbic acid (DHAA) (Singh and Rajini, 2004)

Despite a decrease in the ascorbic acid, the increase in the total phenolic content and DPPH scavenging activity has been reported in the present study. A decrease of ascorbic acid, an increase of antioxidant activity was also reported in tomato products processed at high temperatures (Nicoli et al., 1997; Dewanto et al., 2002) and ascorbic acid content was negatively correlated with FRAP values in berries (Pantelidis et al., 2007). Decreased ascorbic acid content accompanied with high antioxidant activity in thermal dried sweet potatoes could be joined with ascorbic acid oxidation and phenol regeneration (Pantelidis et al., 2007; Yang et al., 2010).

Drying of basil samples resulted change in color. The average values of the color parameters for basil in fresh, after sun and microwave-drying are presented in Table 2 for $L^{*}$ (brightness), $a^{*}$ (redness), $b^{*}$ (yellowness), chroma, hue angle and color change. The $L^{*}$ value represents the change in the lightness level of a sample and is useful to judge the brownness and darkness of leaves after drying. The values for the $L^{*}, a^{*}$, and $b^{*}$ coordinates of the fresh basil were $55.14,-17.13$ and 27.76 , respectively. The values for the $L^{*}, a^{*}$ and $b^{*}$ coordinates of the sun-dried and microwave dried basil samples were $45.63,-1.73,16.79$, and $39.17,-12.19,21.62$, respectively. Microwave drying produced no remarkable changes in the color parameters of basil samples as compared with the fresh basil. However, sun drying allowed both coordinates $L^{*}$ and $a^{*}$ to rise and $b^{*}$ coordinate to decrease. The total color difference $\Delta E$, which is a combination of the $L^{*}, a^{*}$ and $b^{*}$ values is a colorimetric parameter extensively used to characterize the variation of color in foods during processing.

The fresh basils results were consistent with the results of Śledź et al. (2013), but the $\Delta E$ result of the microwave dried sample which in the present study was higher than it. However, similarly, a decrease was observed when the results of microwave dried samples were compared. $L^{*}, a^{*}$ and $b^{*}$ values found in another study on Basil were lower than the results obtained in the present study. But the Chroma value was approximately the same. In the same study, the $\Delta E$ result for the sun dried sample coincided with the result of the present study (Bušić et al., 2014). The decrease of $a^{*}$ and $b^{*}$ values may be due to decomposition of chlorophyll and other pigments and non-enzymatic reactions (Maskan, 2001). The 
browning reactions occurring during drying can have a significant impact on the final color of the product. The enzymatic reaction due to PPO and Maillard reaction are the contributing factors to this change in color. The total color difference $\Delta E$, which is a combination of the $L^{*}, a^{*}$ and $b^{*}$ values is a colorimetric parameter extensively used to characterize the variation of color in foods during processing. The color difference parameter had a value of 21.16 to the basil sun-dried and decreased to 17.81 the microwave dried samples.

\section{Conclusion}

Studies about health promotion by plant phytochemicals have been increasingly attracting the attention of scientists. The results of the present work showed that dried plant materials contain higher total phenolics and antioxidants, drying enhanced antioxidant activity by the increasing of phenolic compounds rate. However, from the results of the present study, it was possible to conclude that thermal drying caused a serious degradation of ascorbic acid and made color changes in basil samples.

\section{Compliance with Ethical Standard}

Conflict of interests: The authors declare that for this article they have no actual, potential or perceived the conflict of interests.

Ethics committee approval: No animals are used in this study

\section{References}

Açıkgöz, F.E., Şahin, F.H., Altan, D.D. (2015). Kuzukulag1 (Rumex acetosa L.) bitkisinin farklı kurutma yöntemleri kullanılarak kurutulması ve kalite özelliklerinin belirlenmesi. Namık Kemal Universitesi Arastırma Projesi,Tekirdağ, Turkey.

Ames, B.N. (1983). Dietary carcinogens and anticarcinogens: oxygen radicals and degenerative diseases. Science, 221, 1256-1263.

https://doi.org/10.1126/science.6351251

Barbosa-Canovas, G.V., Fontana, A. J. Jr., Schmidt, S.J., Labuza, T.P. (2008). Water activity in foods: Fundamentals and applications. John Wiley \& Sons, 440 pages. https://doi.org/10.1002/9780470376454
Ateş, D.A., Erdoğrul, Ö.T. (2003). Antimicrobial activities of various medicinal and commercial plant extracts. Turkish Journal of Biology, 27, 157-162.

Bayala, B., Bassole, I.H.N., Gnoula, C., Nebie, R., Yonli, A., Morel, L., Figueredo, G., Nikiema, J.B., Lobaccaro, J.M.A., Simpore, J. (2014). Chemical composition, antioxidant, anti-inflammatory and anti-proliferative activities of essential oils of plants from Burkina Faso. PLoS ONE, 9(3), 92122.

https://doi.org/10.1371/journal.pone.0092122

Bušić, A., Vojvodić, A., Komes, D., Akkermans, C., Belščak-Cvitanović, A., Stolk, M., Hofland, G. (2014). Comparative evaluation of $\mathrm{CO}_{2}$ drying as an alternative drying technique of basil (Ocimum basilicum L.) - The effect on bioactive and sensory properties. Food Research International, 64, 34-42.

https://doi.org/10.1016/j.foodres.2014.06.013

Chang, C.H., Lin. H.Y., Chang, C.Y., Liu, Y.C. (2006). Comparisons on the antioxidant properties of fresh, freezedried and hot-air-dried tomatoes. Journal of Food Engineering, 77, 478-485.

https://doi.org/10.1016/j.jfoodeng.2005.06.061

Chism, G.W., Haard, N. F., in Fennema, (Ed.) O.R. (1996). Food Chemistry, Dekker, New York, pp. 943-1011.

Choi, Y., Lee, S. M., Chun, J., Lee, H.B., Lee, J. (2006). Influence of heat treatment on the antioxidant activities and polyphenolic compounds of shiitake (Lentinus edodes) mushroom. Food Chemistry, 99, 381-387.

https://doi.org/10.1016/j.foodchem.2005.08.004

de Torres, C., Diaz-Marotoa, M.C., HermosinGutierrezc, I., Perez-Coelloa, M.S. (2010). Effect of freezedrying and oven-drying on volatiles and phenolics composition of the grape skin, Analytica Chimica Acta, 660, 177-182. https://doi.org/10.1016/j.aca.2009.10.005

Demirhan, E., Özbek, B. (2009). Color change kinetics of microwave-dried basil. Drying Technology, 27, 156-166. https://doi.org/10.1080/07373930802566101 
Dewanto, V., Wu, X.Z., Adom, K.K., Liu, R.H. (2002). Thermal processing enhances the nutritional value of tomatoes by increasing total antioxidant activity. Journal of Agriculture and Food Chemistry, 50, 3010-3014.

https://doi.org/10.1021/jf0115589

Erdoğrul, Ö.T. (2002). Antibacterial activities of some plant extracts used in folk medicine. Pharmaceutical Biology, 40, 269-273.

https://doi.org/10.1076/phbi.40.4.269.8474

Gajula, D., Verghese, M., Boateng, J., Walker, L.T., Shackelford, L., Mentreddy, S.R., Cedric, S. (2009). Determination of total phenolics, flavonoids and antioxidant and chemopreventive potential of basil (Ocimum basilicum L. and Ocimum tenuiflorum L.). International Journal of Cancer Research, 5(4), 130-143.

https://doi.org/10.3923/ijcr.2009.130.143

Gross, M. (2004). Flavonoids and cardiovascular disease. Pharmaceutical Biology, 42, 21-35.

https://doi.org/10.3109/13880200490893483

Harbourne, N., Marete, E., Jacquier, J.C., O'riordan, D. (2009). Effect of drying methods on the phenolic constituents of meadowsweet (Filipendula ulmaria) and willow (Salix alba). Food Science and Technology, 42, 1468-1473.

https://doi.org/10.1016/j.lwt.2009.05.005

Hatano, T., Kagawa, H., Yasuhara, Okuda, T. (1988). Two new flavonoids and other constituents in licorice root: their relative astringency and scavenging effects. Chemical Pharmaceutical Bulletin, 36, 2090-2097.

https://doi.org/10.1248/cpb.36.2090

Hışıl, Y. (1993). Enstrümental gıda analizleri laboratuvar kılavuzu. EU Mühendislik Fak. Çoğaltma Yayınları No.55, İzmir, $45 \mathrm{p}$.

Hossain, M., Barry-Ryan, C., Martin-Diana, A.B., Brunton, N. (2010). Effect of drying method on the antioxidant capacity of six Lamiaceae herbs. Food Chemistry, 123(1), 85-91.

https://doi.org/10.1016/j.foodchem.2010.04.003
Javanmardi, J., Stushnoff, C., Locke, E., Vivanco, J.M. (2003). Antioxidant activity and total phenolic content of Iranian Ocimum accessions. Food Chemistry, 83, 547-550.

https://doi.org/10.1016/S0308-8146(03)00151-1

Jay, J.M. (2000). Modern food microbiology. sixth edition. Aspen Publishers, Maryland. 635 p.

https://doi.org/10.1007/978-1-4615-4427-2

Kuljarachanan, T., Devahastin, S., Chiewchan, N. (2009). Evolution of antioxidant compounds in lime residues during drying. Food Chemistry, 113, 944-949.

https://doi.org/10.1016/j.foodchem.2008.08.026

Lin, S.D., Sung, J.M., Chen, C.L. (2011). Effect of drying and storage conditions on caffeic acid derivatives and total phenolics of Echinacea purpurea grown in Taiwan. Food Chemistry, 125: 226-231.

https://doi.org/10.1016/j.foodchem.2010.09.006

Makri, O., Kintzios, S. (2007). Ocimum sp. (Basil): Botany, cultivation, pharmaceutical properties, and biotechnology. Journal of Herbs, Spices and Medicinal Plants, 13, 123-150. https://doi.org/10.1300/J044v13n03 10

Maskan, M. (2001). Kinetics of color change of kiwi fruits during hot air and microwave drying. Journal of Food Engineering, 48, 169-175.

https://doi.org/10.1016/S0260-8774(00)00154-0

Matthäus, B. (2002). Antioxidant activity of extracts obtained from residues of different oilseeds. Journal of Agricultural and Food Chemistry, 50, 3444-3452.

https://doi.org/10.1021/jf011440s

Muller, J., Heinds, A. (2006). Medicinal and aromatic plants, drying of medicinal plants. Edited by R.J. Bogers, L.E. Craker, D. Lange. Springer, Netherlands, pp. 237-252.

https://doi.org/10.1007/1-4020-5449-1_17

Neuhouser, M.L. (2004). Dietary flavonoids and cancer risk: Evidence from human population studies. Nutrition and Cancer, 50, 1-7. https://doi.org/10.1207/s15327914nc5001_1 
Nicoli, M.C., Anese, M., Parpinel, M.T., Franceschi, S., Lerici, C.R. (1997). Loss and/or formation of antioxidants during food processing and storage. Cancer Letters, 114, 7174.

https://doi.org/10.1016/S0304-3835(97)04628-4

Pantelidis, G.E., Vasilakakis, M., Manganaris, G.A., Diamantidis, G. (2007). Antioxidant capacity, phenol, anthocyanin and ascorbic acid contents in raspberries, blackberries, red currants, gooseberries and cornelian cherries. Food Chemistry, 102, 777-783.

https://doi.org/10.1016/j.foodchem.2006.06.021

Putievsky, E., Galambosi, B. (1999). Production systems of sweet basil. Edited by R. Hiltunen, Y. Holm. Basil: The genus Ocimum (Vol. 10). Harwood Academic Publishers, Amsterdam, pp. 39-65.

Ranilla, L.G., Kwon, Y.I., Apostolidis, E., Shetty, K. (2010). Phenolic compounds antioxidant activity and in vitro inhibitory potential against key enzymes relevant for hyperglycemia and hypertension of commonly used medicinal plants, herbs and spices in Latin America. Bioresource Technology, 101, 4676-4689.

https://doi.org/10.1016/j.biortech.2010.01.093

Robards, K., Prenzler, P.D., Tucker, G., Swatsitang, P., Clover, W. (1999). Phenolic compounds and their role in oxidative processes in fruits. Food Chemistry, 66, 401-436. https://doi.org/10.1016/S0308-8146(99)00093-X

Simon, J.E., Chadwick, A.F., Crake, E. (1984). Herbs: An indexed bibliography, 1971-1980. The scientific literature on selected herbs and aromatic and medicinal plants of the temperate zone. CT: Archon Books, Hamden. 770 p.
Simon, J.E., Morales, M.R., Phippen, W.B., Vieira, R.F., Hao, Z. (1999). Basil: a source of aroma compounds and a popular culinary and ornamental herb, Edited by J. Janick. Perspectives on new crops and new uses. ASHS Press, Alexandria, pp. 499-505.

Singh, N., Rajini, P.S. (2004). Free radical scavenging activity of aqueous extract of potato peel. Food Chemistry, 85, 611- 616.

https://doi.org/10.1016/j.foodchem.2003.07.003

Siti Mahirah, Y., Rabeta, M.S., Antora, R.A. (2018). Effects of different drying methods on the proximate composition and antioxidant activities of Ocimum basilicum leaves.

Food Research, 2(5), 421-428.

https://doi.org/10.26656/fr.2017.2(5).083

Śledź, M., Nowacka, M., Wiktor, A., Witrowa-Rajchert, D. (2013). Selected chemical and physico-chemical properties of microwave-convective dried herbs. Food and Bioproducts Processing, 91, 421-428.

https://doi.org/10.1016/j.fbp.2013.02.010

Yang, J., Chen, J., Zhao, Y., Mao, L. (2010). Effects of drying processes on the antioxidant properties in sweet potatoes. Agricultural Sciences in China, 9, 1522-1529. https://doi.org/10.1016/S1671-2927(09)60246-7

Yu, L. (2001). Free radical scavenging properties of conjugated linoleic acids. Journal of Agricultural and Food Chemistry, 49, 3452-3456.

https://doi.org/10.1021/jf010172v 